\title{
A POLITICA ENERGÉTICA BRASILEIRA NA ERA DA GLOBALIZAÇÃO: ENERGIAE CONFLITOS DE UM ESTADO EM DESENVOLVIMENTO
}

\author{
José Alexandre Altahyde Hage
}

\begin{abstract}
RESUMO
O texto tem o intuido de demonstrar que a globalização não tem contribuído amplamente para a vantagem dos estados em desenvolvimento devido à dificuldade que eles têm em construir seu poder nacional. Nesse caso, a própria globalização pode ser utilizada como meio de concentrar influência nos estados industrializados, dificultando o relacionamento entre os dois lados. O intuito do texto é também examinar como essas questóes correspondem ao papel que o Brasil poderá representar como produtor de etanol e petróleo em grande escala. Por fim, o artigo procura compreender em que medida o país poderá transformarse em um importante produtor de energia e, ao mesmo tempo, construir seu poder nacional na era da globalização.
\end{abstract}

PALAVRAS-CHAVE: poder nacional brasileiro; globalização; política internacional; energia.

\section{INTRODUÇÃO}

O objetivo deste artigo é demonstrar quão importante é a constituição de planejamento estratégico para a consecução de segurança energética dos estados, mesmo na era da globalização ${ }^{1}$. Sem querer basear-se em lugarcomum atualmente tão em voga nos temas de política energética, o intuito do texto é sublinhar que a consecução de segurança energética deve ser relevante tanto para países importadores quanto para exportadores de energia. Por isso, há de se melhor compreender os casos de países

1 Conceitualmente, os "estados" são atores que procuram sobreviver em ambiente naturalmente conflituoso. Desde Hobbes, passando pelos pensadores da geopolítica (um componente do realismo em Haslam (2006)), como Ratzel. Assim, o Estado usa a estratégia como ferramenta de sua consecução para sobreviver. No momento em que há estados modernos, com o mínimo de base econômica e política, a sobrevivência ocorre com maior qualidade à medida que haja segurança energética, caso mais específico dos hidrocarbonetos que impulsionam a economia internacional. Daí a premissa de que há segurança energética, integrando as grandes preocupações da segurança no propósito mais largo do termo, como a nacional, que conta com instrumentos militares (RIFKIN, 2002). em desenvolvimento, caso o Brasil, que nos últimos anos tem ganhado relevância na política internacional, entre outras coisas, em virtude de sua excelência na produção de etanol e da importância das jazidas petrolíferas da Bacia de Santos.

Para tanto, é necessário apresentar pontos históricos que marcam a evolução, crise e resposta da política energética nacional de alguns estados em desenvolvimento e sua relação com fenômenos internacionais, como a globalização e a disputa pela proeminência sobre recursos naturais, especialmente o petróleo, cuja importância está acima de dúvidas para o equilíbrio estratégico dos estados em geral. Assim, o artigo faz um breve balanço de algumas questões dos anos 1980 com seus desdobramentos que influenciaram a formação de políticas públicas do Brasil e outros estados em desenvolvimento.

Em princípio, o tema envolve particularmente o Brasil, que tem ganhado sofisticação tecnológica na produção de álcool combustível e na pesquisa e prospecção de petróleo e gás natural em áreas de difícil acesso. No entanto, para que o país possa tirar proveito dessas riquezas é necessário superar dificuldades políticas e institucionais 
ampliadas na história recente, como a falta de perspectiva de construir seu poder nacional para, justamente, aproveitar suas riquezas.

Nos anos 1980 grandes esforços institucionais passaram a ser feitos com o objetivo de separar a esfera econômica da política como se elas fossem duas entidades naturalmente divergentes. Separar a economia da política não seria somente resguardar uma atividade socioeconômica da outra, pois haveria de atribuir-se valores e qualificações morais a uma delas, sendo a primeira positiva e a segunda negativa ${ }^{2}$. Separar a economia da política significava ampliar os direitos considerados naturais (e individuais) da produção econômica e da liberdade de mercado, mesmo sobre aqueles setores vistos como tão caros à estabilidade dos estados, como o energético, sempre passível de conflitos.

Nessa óptica, a esfera política, simbolizada pelo Estado, seria perniciosa ao mercado auto-regulável, que prescinde de planejamento governamental, pelo fato deste desconhecer a real dimensão que envolve os agentes econômicos, cuja máxima é a de que o progresso e o bem-estar só emergem na medida em que as regras da economia de mercado são admitidas. Uma dialética de confrontos foi observada no cotidiano dos estados nacionais, industrializados ou não. Para Julien Freund, de um lado estão os membros do "partido do Direito Privado", os indivíduos, fazendo valer seus direitos sobre seus oponentes, os membros do "Direito Público", a coletividade (FREUND, 1986).

Nesse campo, na visão tradicional de Carl Schmitt, as implicações de elevar o papel representado pela coletividade, do Direito Público acima das individualidades, acarretam o fortalecimento do poder do Estado, do fomentador de estratégia, que faz valer o princípio de soberania e da vontade nacional das unidades políticas ${ }^{3}$ sobre convenções e tratados limitadores (SCHMITT, 1992).

2 Não ignoramos os motivos que levaram à reforma institucional dos anos 1990 no Brasil, como a "crise do projeto de substituição de importações". Deve-se atentar, no entanto, para a qualidade dos resultados daquelas iniciativas para a projeção para projeto de desenvolvimento. Ver texto de Maria da Conceição Tavares (1999).

3 O conceito de "unidade política" pode ser usado como substantivo a "Estado nacional". Começando com Carl Schmitt e Raymond Aron, a unidade política significa um
É claro que todos os fenômenos políticos e culturais tendem a universalizar-se, ainda mais em ambiente interligado por meio de novas tecnologias de comunicação, como a internet. Porém, isso não é algo necessariamente exclusivo dos anos 2000. Nas devidas proporções, no decorrer dos séculos XIX e XX podem ser constatados traços de revolução tecnológica que impulsionaram intercâmbios internacionais em alto grau nas trocas comerciais, nos serviços financeiros e outros itens que haviam ganhado dimensão com o telégrafo e a navegação a vapor; depois com o motor a combustão. No século XIX Marx e Engels haviam percebido o choque tecnológico inerente ao capitalismo como acelerador dos processos socioeconômicos que integrariam variados povos, a saber, processo civilizador rumo ao progresso (MARX \& ENGELS, 1982).

Assim, o fenômeno denominado globalização que, dependendo da análise, ganha ares de novidade e de revolução, com força suficiente para alterar as formas com as quais o sistema internacional organiza-se e compreende-se, não marca presença em somente uma esfera do planeta $^{4}$. Trata-se de atmosfera cuja influencia estende-se às atividades políticas, culturais e econômicas tanto nos Estados Unidos quanto no Japão; e não deixaria de ser presente nos países latino-americanos.

No entanto, há uma diferença que merece ser sublinhada. Embora o processo de globalização

determinado território, ocupado por coletividade possuidora de cultura e identidade, que é organizada por alguma soberania. Esse poder soberano utiliza a guerra para fazer valer seus interesses em situação de conflito. Em Aron, unidades políticas puderam ser encontradas em Atenas e Roma do período clássico, assim como na Florença de Maquiavel e na Alemanha Imperial de Bismarck (ARON, 1986).

4 Não é demais conceituar alguns termos consagrados na literatura de Ciência Política e de Relações Internacionais. Por sistema internacional concebe-se uma relação de coordenação, cujo centro tem a cadência das grandes potências. Os estados nacionais relacionam-se a partir de código de conduta, seguindo comportamentos considerados universais, pois são encontrados em todo o mundo, por exemplo, adoção do trabalho diplomático e embaixadas, compreensão do modo como se organizam forças militares e outros. A posição que o Estado ocupa na ordem das coisas, posição de destaque e secundária, é resultado de processo histórico e político. Na percepção de Waltz, o que determina a posição do Estado no sistema é resultado da estrutura mundial de poder (WALTZ, 2002). 
seja algo de teor universal, ele não se aplica de modo uniforme e constante em todas as unidades políticas que compõem o sistema internacional. A forma com a qual a globalização manifesta-se, política e economicamente, depende da qualidade do poder nacional de cada Estado. Vale dizer, seus efeitos modificam-se quantitativa e qualitativamente em consonância com o poder político de cada unidade política. Dessa forma, seria ilícito dizer que os efeitos globalizantes, bem como sua mensagem, são adotados considerando o perfil político dos próprios estados, conforme pensa Peter Gowan (2003).

A expressão “poder nacional” é usado na Ciência Política, em sua versão mais tradicional, para contabilizar potencialidades dos estados. Trata-se de estimativas, um cálculo de aproximação que leva em conta os fatores básicos de poder, como as riquezas naturais, as forças armadas bem equipadas, a economia avançada, a ciência, a educação popular, a saúde, o número de doutores etc. São fatores que variam de tempo em tempo, mas sem sofrer grandes alterações. No caso brasileiro, há conforto em alguns itens do poder nacional, mas há problemas em outros ${ }^{5}$.

É factível o entendimento de que a globalização seja resultado de avanços tecnológicos em informática, comunicação e novas engenharias. Mas também deve ser compreendido que outros itens concorreram para sua emergência com teor de transformação radical nos anos 1980 e 1990. Talvez o mais explícito disso tenha sido a crise do Estado que grassou por aqueles anos, cujo efeito não se esgotou totalmente. Crise do poder estatal que pode ter deixado sua marca nas grandes potências, mas cujo efeito fora largamente devastador nas áreas mais empobrecidas do globo.

E aqui há um imbróglio. Por que os efeitos socioeconômicos da globalização recebem diferentes admissões? Na parte periférica do sistema internacional ocorrem crises na arena

\footnotetext{
5 Há variedade de analistas que se interessam pelo poder nacional, cada um no seu estilo e época. Há preocupações sobre o poder nacional em Gramsci, Morgenthau e Aron. Na perspectiva brasileira temos Araújo Castro (1999) e Oliveiros Ferreira (2001). O segundo escreveu um livro fazendo um balanço do desgaste do poder nacional e comparando seu desenvolvimento e impasse em duas épocas, período militar e redemocratização.
}

econômica que se estendem na criação de empregos, nas garantias trabalhistas, nas políticas públicas. Entre outros, esses são os frutos do que se pode ler como crise do Estado. Já no mundo desenvolvido a globalização acontece, mas com menor possibilidade de desgastar a esfera pública e o poder nacional.

Partindo da premissa de alguns analistas, como Rubens Ricupero, há como perguntar se o processo que desemboca na globalização não tem cores de ideologia. A saber, ideologia pelo fato de haver uma pregação intelectual, uma opinião institucionalmente montada a seu favor, dando a entender que sua mensagem e resultado são expressões universais que desconhecem fronteiras, abarcando tanto em vantagem quanto em impasses todo tipo de Estado, ricos e pobres (RICUPERO, 2002).

Essa ideologia, para o ex-embaixador brasileiro, não sobrevive aos testes da realidade. De fato, não há como negar que a revolução tecnológica contribui com a globalização e o estreitamento das relações internacionais. Contudo, tratando-se da América Latina, tem de observar-se que as crises econômicas e sociais da região foram os custos do baixo poder nacional para que a globalização, e o que ela simboliza, ascendesse (idem). Por isso, o abandono de projetos nacionais de desenvolvimento, da autonomia industrial e da tecnologia, são fatos que aconteceram para dar lugar às sugestões feitas por organizações internacionais e sua ideologia anti-Estado (CANO, 2000).

Outra sugestão que ganhou espaço nos debates políticos nos anos 1990 foi a que seria factível adotar modelo antigo, mas ainda útil, de coordenação produtiva, o mercado auto-regulável que seria muito mais compatível com o período posterior à Guerra Fria do que os desgastados programas de planejamento governamental, sendo boa parte deles sinônimo de ineficiência e antiracionalidade econômica, conforme escrevera Friedrich Hayek contra o keynesianismo (HAYEK, 1986).

A idéia acima relembra estudos feitos por Karl Polanyi para analisar o princípio do mercado autoregulável, no século XIX, e por que esse mercado entrou em decadência nos anos 1930 com os nacionalismos (POLANYI, 2000). Ignorar os contratempos que o autor de $A$ grande transformação escreveu para privilegiar grupos de 
investidores internacionais e domésticos como se, efetivamente, houvesse analogias políticas, sociais e econômicas para reproduzir o modelo liberal do século retrasado talvez tenha sido um dos grandes equívocos que houve nas tomadas de decisão dos governos, sobretudo dos Estados em desenvolvimento (GRAY, 1999).

O estudo do ambiente político e econômico que envolve questões energéticas e o papel que o Brasil representa nesse espaço é o objetivo deste texto. Ambiente que, por vez, assiste ao lançamento de pregações como a do mercado autoregulável e aos pressupostos de que há uma globalização da energia, de que se ela fosse bem seguida traria desenvolvimento e bem-estar aos países envolvidos.

\section{A GLOBALIZAÇÃO E A IDEOLOGIA DO MERCADO AUTO-REGULÁVEL}

O princípio de um mercado auto-regulável como pressuposto de racionalidade econômica e maximização de ganhos para operadores capacitados e competentes não é exclusividade do período de globalização. Dessa forma, o intuito deste texto não é impulsionar o debate da antiglobalização nem se fixar em um setor específico dela, a economia. Cada vez mais, falar em globalização tem sido tarefa difícil, uma vez que se multiplicam textos feitos para analisá-la, permitindo variedade enorme de opiniões. Opiniões que nem sempre se pautam pela qualidade, mas sim pela quantidade, reproduzindo máximas de lugares-comuns e não reparando no viés ideológico.

Dizer que a globalização abarca todos os estados, ricos e pobres, centrais e periféricos, nos mesmos efeitos e desgastes, é algo que se torna inadequado, pois privilegia a visão fatalista de que a política necessária, que se deseja para dar destaque ao desenvolvimento dos Estados, não mais existe. Então, o que fazer com o desemprego e o atraso tecnológico, por exemplo? Para governos conformistas, sem vontade nacional para sanar as grandes questões sociais e econômicas a globalização tem sido um bálsamo para servir de justificativa e para esquivarem-se de responsabilidades, de acordo com a leitura de Paulo Nogueira Batista Júnior (1997).

É fato que a globalização não é versada somente nos assuntos econômicos e tecnológicos. Da mesma forma, não há como imaginar que todos seus debates sejam para demonstrar seus efeitos negativos ${ }^{6}$. No entanto, não é difícil encontrar críticos, sobretudo de sua versão econômica, Joseph Stiglitz (2003) e Gowan (2003), só para citar dois. Eles são da opinião de que a globalização, além de não ter consistência em sua mensagem virtuosa, como o aumento do comércio internacional, pode ser ainda encarada como "instrumento de laboratório" a favor das grandes potências. Em outras palavras, a globalização é uma ideologia, da mesma forma que foi ideologia a pregação da nova ordem internacional nos anos 1990 e suas derivações com o "fim da história", que tanto espaço teve com o desmanchar do socialismo soviético.

Ideologia porque, em primeiro lugar seria errôneo sublinhar que os fluxos de comércio internacional gozam de trânsito como nunca visto na história, tudo em virtude do final da GuerraFria e da decadência dos princípios estratégicos nacionais, da política propriamente dita. A liberdade econômica e seus resultados no comércio internacional já tiveram dias melhores, mesmo antes desse tipo globalização, acredita Batista Júnior, cujo pensamento é o de que no período da Pax Britannica, entre 1870 e 1914, a liberdade comercial foi maior que a atual.

Mais do que isso, mesmo sob governos conservadores, antiliberais, portanto afeito ao protecionismo, o Reino Unido fora mais aberto ao mercado externo durante sua proeminência político-econômica do que sua representação atual, assumindo o livre-mercado. Havia mais liberdade comercial e social, trabalhadores imigrantes, no começo do século XX, em comparação ao que ocorre na "era da globalização", em que as fronteiras passam a ser vigiadas constantemente e a imigração transforma-se em questão nacional. Assim, não seria original pregar que os princípios de livre-mercado e liberdade social são algo inerente à globalização nos anos 1990. No fundo, com as devidas proporções, os fluxos atuais do

6 Octavio Ianni faz uma leitura diversa da globalização. Seus efeitos podem ter outra representação para movimentos sociais que queiram escapar do nacional e pleitear militância internacional, valorizando o socialismo. Uma sociedade civil internacional que cresceria à medida que o poder político dos estados entrasse em decadência. Sociedade civil internacional que estaria acima dos estados, e suas querelas, e tendo como ponto primordial a valorização do homem completo e sua liberdade - o que seria, para Ianni, a renovação do marxismo (IANNI, 1997). 
comércio internacional seriam até inferiores aos contabilizados pelo sistema anterior à I Guerra Mundial (THOMPSON \& HIRST, 2002).

Para concluir esse ponto, Keynes escreve que se criticava a Rússia czarista porque ela exigia passaportes de europeus ocidentais que quisessem entrar em seu território. Pedir passaporte seria sinal de atraso, resquício de um país que ainda não havia adentrado à modernidade da energia elétrica etc. Assim, livre-trânsito era sinal de civilização (KEYNES, 2002). Quer dizer, a União Européia acabou restituindo uma prática que havia se perdido por causa das guerras.

Em segundo lugar, porque a globalização não seria algo fatalista, sem participação humana, sob a qual as sociedades têm de adaptar-se para minorar seus efeitos, mas sim um instrumento fomentado pela revolução tecnológica. Vale dizer, um arcabouço formulado pelos blocos nacionais de poder ${ }^{7}$ encontrados tanto nos Estados Unidos quanto no Reino Unido para restaurarem sua preeminência internacional, pressionando aberturas comerciais e desregulamentações (GOWAN, 2003).

No juízo de Chang, no âmbito das políticas públicas utilizadas por unidades desenvolvidas, Estados Unidos e Europa Ocidental, constata-se que instrumentos de proteção ao mercado doméstico, apoio institucionais a empresários, subsídios a exportações etc., foram e, em algumas

7 Preferimos a expressão "blocos nacionais de poder" para analisarmos o conjunto que engloba não somente $o$ governo, mas também empresas, partidos políticos e intelectuais que fecham opinião sobre alguma política. No caso dos Estados Unidos e do Reino Unido, em primeiro plano, o bloco nacional de poder é formado pelos seus respectivos mandatários, com apoio de dirigentes empresariais e think tanks que dão cobertura intelectual às suas escolhas. Tratando-se de energia, não seria incongruente a existência de bloco político que procura assegurar suprimentos de hidrocarbonetos nos locais mais hostis, como Ásia Central. Hannah Arendt havia comentado que o primeiro impulso para a expansão política, econômica e militar para o exterior em busca de recursos, imperialismo, dá-se pela existência de grupo específico, unindo o público e privado, que cria condições intelectuais e políticas para tal excursão (ARENDT, 1989). Na atualidade, o resultado dessa empreitada tende a ser uma competição pelos recursos energéticos que ainda existem nas proximidades da Ásia Central, retomando a máxima de Mackinder, segundo a qual quem se apossa desse heartland adquiri vantagens perante seus competidores. Nesse caso, os concorrentes são Estados Unidos, Rússia e China (HARVEY, 2004). partes, ainda são, muito presentes na participação desses países na economia internacional, embora a cultura política geral indique o contrário. Mas, por outro lado, utilizam-se argumentos montados para demover os estados periféricos dos mesmos instrumentos que levaram Washington, Londres e outras a serem centros de estados industrializados (CHANG, 2004).

Em outro diapasão, os desdobramentos da globalização na Argentina e Brasil, receberiam outro impulso, pela crise institucional e econômica que esses estados latino-americanos passaram com a quebradeira da dívida externa dos anos 1980, a moratória mexicana. O forte desgaste dos Estados da região, impedindo-os de continuar linhas de desenvolvimento iniciadas nos anos 1950 e 1960, foi conveniente para decretar o fim das autonomias econômicas e adotar planos de desregulamentação e reformas que davam a entender o quanto o período desenvolvimentista fora negativo para firmar o crescimento econômico e a distribuição de renda.

Voltar a crescer economicamente nos estilos mais desenvolvidos, bem como afirmar franquias liberais em Estados vitimados por governos autoritários, só poderia ser feito por meio de reformas que diminuíssem (ou excluíssem) o papel regulador dos estados na esfera produtiva $\mathrm{e}$ de serviços afeitos a monopólio natural, como energia elétrica e telefonia. A partir desse ponto, as privatizações passaram a ser esperadas com a eleição de plataformas governamentais que fossem mais receptivas às sugestões de algumas organizações financeiras internacionais, como o Banco Mundial, cujo debate era o de que em fase de livre-mercado não haveria mais por que continuar com planos de desenvolvimento autárquicos ${ }^{8}$, o que valia também para aqueles setores

8 No Brasil quem, de certa forma, encarou a missão de militar pela economia de mercado e superar todas as formas o antigo modelo de desenvolvimento foi o ex-Senador Diplomata Roberto Campos. No papel de "intelectual orgânico" das reformas, Campos imprimia uma espécie de representação que aliava experiência política e ironia com a qual apelidava com os termos "petrossauro" e "valessauro", respectivamente Petrobrás e Vale do Rio Doce (CAMPOS, 1994). No governo de Fernando Henrique Cardoso a verve de Campos pode tê-lo inspirado no percurso a favor da desregulamentação por meio de palavras usadas com o intuito de diminuir política e intelectualmente o interlocutor, por exemplo, "neobobos" (GRÜN, 2005) 
que foram considerados estratégicos nos últimos 50 anos, como a energia (BERMANN, 1991).

Algumas afirmações podem incomodar quem honestamente trabalhou pela desregulamentação dos serviços públicos, acreditando que realmente estavam fazendo um bem para o Estado, na criação de empregos e na distribuição de riquezas para a sociedade. Lendo autores que foram engajados na tentativa de ter-se maior harmonia internacional, sob a égide da globalização, é possível encontrar quem tenha extraído outra concepção das políticas sugeridas tanto pelo governo norte-americano nos anos 1990, de Bill Clinton, quanto pelas organizações internacionais. Em parte, é o que acontece com o depoimento de ex-Presidente do Banco Mundial, Josef Stiglitz: "Alguns de nossos problemas no exterior eram causados pela forma como interagíamos com os outros países, principalmente com as nações em desenvolvimento, mais fracas. Ao agir como se tivéssemos descoberto uma fórmula única e segura para a prosperidade - às vezes com a ajuda de outros países industriais avançados -, nós intimidamos outras nações a fazer coisas da nossa maneira. Tanto por meio de nossa própria diplomacia econômica como por influência de um Fundo Monetário Internacional sob domínio americano [...]" (STIGLITZ, 2003, p. 51).

Pelo fato de a América Latina ter atravessado grande crise econômica, e de ter entrado com descrédito no sistema financeiro internacional, a reforma do poder público foi recebida com entusiasmo, até por setores intelectuais e políticos à esquerda que negavam o período nacionalista por causa do autoritarismo (BERMANN, 1991). Planos de reformas institucionais que promovessem a diminuição e, em alguns casos anulação, do poder público sobre serviços sociais foram vislumbrados positivamente. Serviços sociais que tradicionalmente foram vistos como de interesse governamental, já que eram passíveis de prejuízo e de lucros parcos, entraram em via de desregulamentação.

Assim, passou a ser aventado pelos governos reformistas, o brasileiro Collor de Mello, em 1990, e Fernando Henrique Cardoso, em 1995; o argentino Carlos Menem, em 1989 e o mexicano de Carlos Salinas, em 1985. O plano era a desregulamentação e privatização com o intuito de fazer ações urgentes em face do difícil período: restabelecer o crédito internacional perdido nos anos 1980 em virtude de moratórias e reconstruir o poder de investimento dos estados em áreas vistas por essenciais para a nova economia que ganhara corpo por meio de criações tecnológicas (CANO, 2000).

Não se trata de fazer crítica moral contra os governantes da ocasião, nem de utilizar termos de pouca precisão conceitual, por exemplo, "neoliberalismo", que tanta linha ocupou nos textos contestadores. Saber se houve efetivamente o emprego do neoliberalismo no Brasil, nos moldes imaginados nos Estados Unidos e Reino Unido, é algo que tem de ser examinado com mais atenção, o que não pode ser feito aqui.

A questão de fundo é que mesmo imbuídos de planos preocupados com a virtude do mercado e dos investimentos privados, internacionais ou não, em serviços públicos mais complexos, ficou claro que as desregulações não lograram resultado esperado, inclusive é o que reconhecem importantes analistas da questão, como José Goldenberg e Luiz Tadeu Prado. O primeiro exerceu cargo de Secretário da Energia durante o governo de Mário Covas, em 1995 e pôde acompanhar os desdobramentos que levou à perda de eficiência do sistema elétrico paulista, com a Eletropaulo e a Companhia Paulista de Força e Luz (CPFL) (GOLDENBERG \& PRADO, 2003).

No caso brasileiro o problema mais premente foi a aceleração da crise de energia elétrica, de 2001, denominada apagão, em virtude da falta de políticas consistentes de coordenação e investimento durante os anos 1990, quando houve forte pressão de agentes econômicos, intelectuais e políticos para que se descaracterizasse o antigo sistema Eletrobrás, criado nos anos 1950, para construir um setor de relevância capital para o desenvolvimento. Embora seja de conhecimento histórico, é bom salientar que houve a empreitada do poder público há mais de 50 anos na construção do setor elétrico nacional. Isso porque não houve interesse, ou capital suficiente, por parte da iniciativa privada. Na leitura de Marcondes Ferraz, que planejara a usina de Paulo Afonso, a entrada do Estado na construção da mencionada planta não seu deu por preconceito contra o capital privado, mas sim porque ele não apareceu (FERRAZ, 1981).

A razão disso é que obras de infraestrutura são grandes absorvedoras de capital intensivo e suas possibilidades de reverter lucros para o 
investidor são baixas em virtude do tipo de "produto" que fornece, bem como as obrigações sociais que detêm. Fornecer serviço social, água ou energia elétrica, não pode ser visto como mercadoria propriamente dita, embora seja necessário que o investidor não se comprometa com dívidas e prejuízos constantes. Este tem sido um debate travado no âmbito não somente na Engenharia e na Economia, mas também na Sociologia, com a teoria do "antivalor"

Voltando à crise do Estado que se fez presente nos anos 1980 e 1990, havia ficado incongruente usar argumentos políticos e intelectuais para conservar o processo de desenvolvimento econômico fundados nos anos 1950. As razões mencionadas foram o desgaste para lidar com itens econômicos muito mais dinâmicos e sofisticados para um sistema baseado na autarquia. Novos meios de comunicação, de informática etc., deveriam ser administrados por agentes governamentais e empresariais, mais sensíveis ao fato de que o fim da Guerra Fria havia sido um divisor de águas entre duas épocas. O processo de substituição de importações havia acabado (DOMINGUES, 2007).

Também não se deve deixar de comentar outros dois itens relacionados com o desgaste do desenvolvimento autônomo e com a crise do Estado, o deficit público e a alta inflação que duraram todos os anos 1980. Dizer que necessariamente o deficit público e inflação são partes integrantes da substituição de importações pode ser impreciso. É certo que bancar a economia nacional com incentivos governamentais e promover o mercado consumidor é algo que exige recursos, sendo boa parte deles provenientes da poupança doméstica, a saber, de tributações e empréstimos internos.

Durante os anos 1950 a 1990 o setor energético brasileiro foi um grande fomentador de incentivo e subsídios para o crescente

9 Estas páginas não são oportunas para analisarmos com pertinência a teoria do antivalor do Sociólogo Francisco de Oliveira. Mesmo assim, para José Paulo Vieira, a energia, como serviço público, não pode ser contabilizada pelos métodos convencionais que o mercado utiliza para produtos convencionais, "lei da oferta e procura". Isso porque o fornecimento de energia elétrica guarda compromisso social que se tiver seu valor reajustado pelas regras do mercado o resultado será o prejuízo de setores populares de baixa renda (VIEIRA, 2007). empresário brasileiro. Com facilidades em infraestrutura e tarifas públicas subsidiadas, as empresas nacionais e internacionais puderam ascender sem riscos de desabastecimentos ou "estouro" de tarifas dos serviços prestados, mesmo em período de dificuldades econômicas, conforme avalia Antonio Dias Leite em seu livro A energia do Brasil (LEITE, 1997).

Nos anos 1980, na forte crise econômica, o Estado brasileiro não usava reajustar tarifas de energia elétrica para adquirir meios de equilibrar a balança doméstica, o que fez que críticos dissessem que tais atitudes eram contraproducentes pelo fato de continuar privilegiando quem tinha condições de pagar e jogar o prejuízo para o Erário. O resultado daquelas operações era o aumento do deficit público e, nascendo deste, a inflação que passara a galopar para números inéditos no país.

Porém, há também uma explicação alternativa, que não se desvincula do grupo afim ao projeto de substituição de importações ou àquilo que derivaria de um Estado com mais poder de afirmação. Assim, a elevação do deficit público e da inflação que castigou a denominada "década perdida" também poderia ser resultado da posição menor e comprometida que o Brasil ocupava no sistema internacional. Posição fraca que fazia que o Estado, junto com os demais da América Latina, pagasse pelo ônus e pelas decisões feitas justamente no campo das grandes potências (DOMINGUES, 2007).

Se houve descontrole da inflação e do deficit público, é porque existiu o encarecimento dos serviços da dívida externa. É congruente recordar que foram dívidas feitas com muito apreço pelos bancos internacionais e com o sinal verde dos governos, mormente dos Estados Unidos, que via muita vantagem naquelas operações de empréstimos para fazer circular os petrodólares, recursos provenientes de meios que haviam aumentado muito por causa da forte subida no preço do barril de petróleo, em 1973 (STIGLITZ, 2003). Mais empréstimos, mais consumo e investimentos com "dinheiro barato", com juros baixíssimos, até negativos para aumentar o fluxo de empréstimos aos estados necessitados de capital. Contudo, havia a letra de que os juros da dívida seriam flutuantes - e a fatura veio cara no momento em que o governo Ronald Reagan subiu os juros no Federal Reserve Board, desgastando 
fortemente o poder de pagamento dos endividados.

Por isso, não é crível somente atribuir o calvário dos enforcados somente à autarquia econômica, mas de igual modo deve-se reparar no papel que houve a partir das tentativas de Reagan para restituir o poder nacional dos Estados Unidos e seus esforços para vencer o embate da II Guerra Fria. O projeto "Guerra nas Estrelas" exigia grandes vultos financeiros. E de onde deveria sair o dinheiro para tal, a não ser das cobranças feitas sobre os estados periféricos?

Desse modo, pode-se observar que alguns impulsos que animavam a globalização nos anos 1990 guardam semelhança com fatores que acabaram sendo substantivos da própria globalização, como liberdade econômica, livre fluxo comercial em todo o mundo e a premissa de que não haveria mais por que gastar tempo com a conformação do poder nacional dos estados, ainda mais os periféricos, uma vez que não haveria mais razão pensar nisso em uma era de decadência soberana. Se a soberania está em seu "ocaso" no Hemisfério Norte, imagina-se, então, o que seria no Sul.

Esses vazios conceituais, institucionais e ideológicos rapidamente passaram a ser ocupado não por uma novidade revolucionária, mas sim pela releitura e reformulação de antigos instrumentos e pregações sob a figura da globalização para legitimar a máxima de que não haveria por que resistir ao fatalismo. Nessa seara apareceram pregações de que surgiria o mercado auto-regulado, da mesma forma que ele existiu no século XIX. Mas, desta vez, sema cultura e a matéria-prima que possibilitou aquela modalidade de mercado. Não houve quem se responsa-bilizasse por ele ${ }^{10}$.

10 Não se trata de histórico norte-americano, despreocupado com a sorte do sistema econômico internacional. Sobre isso pode ter-se outra percepção, mesmo que limitada. É licito frisar que a construção de um tipo de "estabilidade hegemônica" fez-se presente nos anos 1950, até 1973, quando o governo Nixon abandonou o padrão ouro. Nas características da estabilidade hegemônica, Washington tentou estabelecer, sob sua responsabilidade, um regime de livre-comércio em que o importante seria a regularidade que, em princípio, houvesse acato por regras básicas de convivência. Guardando as devidas proporções foi o que fez a Grã-Bretanha no período do livre-cambismo no século XIX (POLANYI, 2000; HOBSBAWN, 1994).
Mesmo sem o ente responsável pelo equilíbrio da economia mundial e sem o regulador necessário, os negócios empresariais tinham de continuar e de ganhar terreno, sobremodo por causa de áreas esgotadas para a rápida maximização de investimentos. O outrora promissor Leste europeu, recém liberado do socialismo, mostrava sinais de esgotamento, inter alia, por causa de grupos nacionais, cujos métodos nem sempre combinava com a moral esperada da virtude do homem econômico. Assim, a energia serviu de atração para atrair investidores na América do Sul por causa da pouca possibilidade de maximizar capital emregiões saturadas, como a Europa Ocidental (SANTOS, 2002).

O leste da Ásia, com os Tigres à frente, também não se mostrara mais interessante. Não pelo impasse do capitalismo, mas sim pelo esgotamento do modelo de expansão econômica, do livre-mercado, que havia entrado em choque com setores governamentais e empresariais da região, o que passou a ocorrer aceleradamente a partir da crise financeira, dos emergentes, que aconteceu em 1997 (STIGLITZ, 2003). Um tipo de nacionalismo asiático contribuiu para que investidores que procuravam novos eldorados passassem a reparar na desgastada América Latina com ativos a serem privatizados.

E a oportunidade chegou justamente com a desregulamentação de setor que dificilmente entraria nesse feito nos anos 1950 a 1980, principalmente nas maiores unidades da região, como Brasil, cujo princípio estratégico foi o de que energia é bem essencial para o arranjo da segurança nacional. E sobre esse princípio não se torna difícil encontrar pronunciamentos e documentos que o comprovam. Analistas já se debruçaram sobre essa afirmação, por exemplo, Oliveiros Ferreira (2001) quando estuda o impacto dos Acordos de Roboré, de 1958, entre Brasil e Bolívia, para a compra de petróleo do vizinho andino, e Christian Caubet (1991), com seu estudo sobre a relação do poder político brasileiro, com a energia, na construção da usina de hidrelétrica de Itaipu $^{11}$.

11 A relação entre poder e energia, como um dos fundamentos do poder nacional brasileiro, está presente na obra do general Golbery do Couto e Silva. Nesse autor a energia tornar-se-ia elemento primordial que deveria ser visto como parte dos "objetivos permanentes" do planejamento estratégico (COUTO E SILVA, 1981). A 


\section{POLÍTICA E ENERGIA NO BRASIL}

A oportunidade para que a América Latina, especialmente o Brasil, adentrasse na globalização energética surgiu com a desregulamentação do setor elétrico em 1995. Naquele ano, o governo de Fernando Henrique Cardoso havia constituído uma base técnica e parlamentar para que a privatização das empresas estaduais de energia elétrica, bem como a descaracterização do sistema Eletrobrás, ganhasse corpo. Claro, não se deve também deixar de comentar que, em paralelo à situação brasileira, havia experiências na Argentina e na Bolívia com a desregulamentação do setor energético deles.

A falta de maximização rápida do capital investido fez que os interessados internacionais, na maior parte, viessem à América Latina com o intuito de adquirir controle de empresas como Eletropaulo (São Paulo) e Light (Rio de Janeiro), importantes firmas públicas que se responsabilizavam pela distribuição de energia elétrica, mas que nos anos 1990 sofriam pela falta de investimento nas estruturas mais sensíveis, que necessitavam de reformas. Vale dizer, havia tempos que tais empresas não recebiam meios para sua readequação técnica (SANTOS, 2002).

De certa forma, a falta de investimento na infraestrutura elétrica não foi sem propósito e veio a calhar para criar legitimidade política para que essas empresas fossem privatizadas. Isto é, a desvalorização operacional e financeira das estatais não era sem propósito, cumpria um plano coerente para melhor transferi-las aos novos investidores (ROSA, 2001). Em algumas situações houve controle externo das firmas de serviços públicos nacionais, visto que o controle acionário passou a residir na Europa Ocidental ou nos Estados Unidos, caso da Light e da Eletropaulo. A primeira sob controle de capital francês; a segunda com comando de investimento norte-americano. Para sublinhar esse impasse vivido pelo Brasil, passamos a palavra a César Benjamin: "Alguns anos antes, em plena era Reagan, os Estados Unidos, pátria do liberalismo, haviam tomando cuidado de preservar sob controle estatal o seu sistema de geração hidroelétrica, parte do qual continua a ser operado diretamente pelo Exército.

premissa ressurge nas reflexões mais contemporâneas, vide Darc Costa, que imputa à integração regional uma das maneiras de o Brasil conseguir regularidade de suprimentos energéticos (COSTA, 2004).
Isso se explica, de um lado, pela necessidade de se preservar nas mãos do Estado o núcleo estratégico do sistema" (BENJAMIN, 2001, p. 60).

No âmbito latino-americano, o emprego do capital internacional fez presença na privatização dos setores elétricos e petrolíferos em quase todo o subcontinente. Na Argentina houve a privatização da Yacimientos Petróleos Fiscales e na Bolívia houve o mesmo feito com a Yacimientos Petróleos Fiscales de Bolívia. No México, grande produtor, não houve, de fato, privatização de sua estatal, mas sua produção ficara como garantia pelo fato de o país ter adquirido um volumoso empréstimo de bancos norte-americanos e do Fundo Monetário Internacional (FMI) para consertar a crise econômica de 1994 (STIGLITZ, 2003). E não seria demais dizer que parte substancial da riqueza mexicana vem do petróleo, boa parte dele exportado para os Estados Unidos.

À primeira vista, o impacto da privatização das antigas empresas de energia elétrica não foi positivo. A escalonada no preço das tarifas foi muito grande em pouco tempo, e foi ainda mais dramático por causa dos setores sociais de baixa renda, cuja tarifa era subsidiada pelo Estado (BALBONTÍN, 1999). Para os novos administradores, muitos deles sem conhecimento adequado da situação latinoamericana (do Brasil em especial) dar subsídios à faixa mais pobre da população seria sem propósito, sobretudo considerando o real debate intelectual que procurava fazer do Brasil um país de economia liberal.

Situação interessante, pois o subsídio deveria ser anulado pelo fato de camuflar a capacidade empresarial do Brasil e também pelo motivo, já suficiente, de ser algo contrário ao espírito da livre-empresa. Porém, não foram poucas as vozes que aceitaram empréstimos a juros baixos feito com recursos públicos do Banco Nacional de Desenvolvimento Econômico e Social (Bndes) e do Fundo de Apoio ao Trabalhador (FAT) para financiar a compra das empresas estatais de energia elétrica por parte dos grupos interessados. Recursos que deveriam ser empregados no bemestar da população de modo geral, e não para privilegiar o capital internacional (SOLNIK, 2001).

A privatização da empresa Petrobrás havia sido planejada no governo de Fernando Collor de Mello, em 1990. Pelo fato de haver muita emoção ligada à historia da estatal, saída da campanha "O Petróleo é Nosso", no auge do movimento 
nacionalista de Getúlio Vargas, certamente não seria nada fácil mover os atores aliados e convencer parte da opinião pública de que a privatização do setor petrolífero nacional seria conveniente para a aquisição de riqueza e bem-estar ao povo.

$\mathrm{Na}$ fórmula do governo Collor e do pessoal do Bndes, que combinava com o plano de privatização, o que o governo deveria fazer era usar a máxima "comer pela beirada"; não se concentrar diretamente na Petrobrás, mas sim naqueles setores estatais que teriam menos resistência política para posteriormente adentrar no campo do petróleo. Assim, com a idéia de que o governo Collor deveria adquirir legitimidade para tais assuntos complicados, houve a privatização do setor petroquímico, considerado menos dramático que o petrolífero propriamente dito, o que resultou na diminuição sensível do Estado nesse setor. Anos depois percebeu-se o erro feito, principalmente porque o Brasil virou importador de fertilizantes, produto altamente ligado à industria petroquímica. Atualmente, o setor tem ausência de capital nacional (SCHUTTE, 2004).

A fórmula de desgastar resistências migrou para o governo Fernando Henrique Cardoso, em 1997. Como seria dramática a ação de privatizarse a Petrobrás, o governo preferiu duas táticas de impacto. A primeira foi quebrar o monopólio nacional do petróleo, feito em 1953, que resguardara a exploração e importação de petróleo à estatal. A segunda tática foi implantar executivos no comando estratégico da empresa, mas que não fossem de carreira. De fato, que não fossem criados na cultura da Petrobrás, sem seu esprit de corps, considerada prejudicial ao processo de privatização.

A razão para isso não seria despropositada. Isso porque havia a tradicional queixa, ao menos dos opositores, de que a Petrobrás seria envolta em uma espécie de "caixa preta", em que as decisões mais prementes da corporação eram resguardadas para o proveito do funcionalismo e sem permitir consultas externas, da sociedade propriamente dita. $\mathrm{Na}$ seqüência dessa queixa havia a opinião de que a estatal teria um poderoso corporativismo que dificilmente permitiria alterações - o que resultaria na premissa de que as decisões em nível federal teriam pouco efeito.

Dessa forma, uma das maneiras de minar o espírito corporativo da petroleira brasileira seria contaminá-la por dentro, botando diretores que pudessem ser escolhidos pela Presidência da República, como o próprio mandatário da empresa. Conseqüentemente, em 2001 era Presidente da Petrobrás alguém que não fora formado em seus quadros, mas sim um executivo escolhido pelo Palácio do Planalto ${ }^{12}$. O indicado para minar as pressões da corporação, rumo à possível privatização, não detinha o conhecimento profissional que lhe permitisse comandar a firma com a eficiência esperada, mesmo que seus objetivos contrariassem o apresentado pelo grosso dos funcionários (GRÜN, 2005).

E foram sintomáticas as escolhas que o governo Fernando Henrique Cardoso fizera para comandar a Petrobrás. Em sua segunda gestão, o ex-Presidente da República havia aceitado a escolha de dois profissionais ligados a empresas privadas e bancos, mas com pouca ligação com a atividade profissional na esfera pública. Francisco Gros e Henri Reichstul eram profissionais formados no campo da iniciativa privada e com formação intelectual nos Estados Unidos e na Grã-Bretanha, em nível de pósgraduação em Economia. Gros ainda tivera certa atividade no Bndes e no Banco Central, mas sempre com atenção voltada para a desregulamentação e no cumprimento da agenda proposta pelo FMI. Já Reichstul era neófito nos meandros da burocracia pública - e foi justamente em suas mãos que surgiu profundo mal-estar.

O mal-estar foi fruto de sucessão de enganos que desembocou no afundamento da Plataforma P-36. Acidente que, de certa forma, abortaria os fitos de privatização, ou o adiaria, sine die, pelo motivo de descrédito e por ter legitimado as queixas feitas pela Associação dos Engenheiros da Petrobrás, de que haveria um plano sinistro feito pelo bloco nacional de poder para privatizála (idem).

12 É licito dizer que a escolha de um funcionário alheio à carreira para a Presidência da Petrobrás é um ato regular Historicamente é o Planalto que escolhe o Presidente da empresa, geralmente alguém que tenha afinidades políticas com o governo. Em 1979 João Figueiredo havia posto Shigeaki Ueki para presidir a Petrobrás. Na posse do Presidente Lula, em 2003, o cargo havia sido do Deputado Federal pelo Partido dos Trabalhadores (PT), José Eduardo Dutra, que foi engenheiro da estatal. De fato, a escolha de Reichstul para presidir a petroleira foi algo bastante simbólico, visto qual era o objetivo do bloco que sustentava Fernando Henrique Cardoso para realizar reformas. 
Nesse aspecto, marca-se uma inflexão no processo de reforma institucional do Estado brasileiro. A imagem de que a iniciativa privada seria mais bem preparada tecnicamente (e não corrupta) para administrar serviços públicos recebeu forte golpe tanto pela crise do apagão, visto que sua gênese fora provocada por duas causas, a falta de investimentos importantes no setor elétrico, agora privatizado, e pelo salto de corrupção feito por um dos grandes acionistas da Eletropaulo, a empresa norte-americana Enron, que havia adentrado no setor elétrico nacional e gozado de mérito superavaliada em sua modernidade em prol do mercado (ROSA, 2001; STIGLITZ, 2003).

Eis um traço polêmico na relação entre governos, partidários da reforma institucional, e empresas que participaram da desregulamentação e das privatizações. Isso porque ficara patente que a lógica de que a corporação privada daria conta do desenvolvimento e bem-estar social no setor em que adentrara, prescindindo de algum apoio do poder público, revelou-se falaciosa (SOLNIK, 2001)

Em 1995, a própria Eletropaulo ficara proibida de fazer atualizações técnicas necessárias, investimentos, para conservar sua competência, reconhecida internacionalmente. Proibiu-se que a empresa, que tinha caixa suficiente, gerasse superavit fiscal. No fundo, havia o pensamento de que o mais urgente seria constituir bons relacionamentos com o FMI para que o Brasil tivesse credenciais atraentes perante o investidor internacional. Nesse propósito, o nome do Fundo serviria como credencial para a boa imagem do País.

Por outro lado, se o Bndes ficara impedido de fazer investimentos nas estatais de energia elétrica, a mesma proibição não ocorreu no momento de emprestar-se recursos públicos para que o empreendimento privado internacional participasse no processo de privatizações, assim é que apareceu a Enron na vida econômica brasileira. Contudo, com a crise de credibilidade e falência da participante norte-americana, em 2000, o que poderia aprofundar ainda mais a crise brasileira de energia elétrica por falta de capital na Eletropaulo, o governo federal teve de direcionar recursos. A saber, não houve autorização de empréstimos do Banco para melhorar a infraestrutura das ex-estatais, mas houve permissão para salvá-las de operações fraudulentas (SOLNIK, 2001). Goldenberg e Prado voltam ao assunto com as seguintes percepções: "Todas essas dificuldades do setor elétrico foram induzindo, paulatinamente, a uma deterioração das reservas do sistema anteriores à reforma. Essa situação era agravada pelo fato de que as geradoras federais que pretendiam fazer novos investimentos para tornar o sistema menos vulnerável foram impedidas de fazê-lo pela política de austeridade fiscal do governo" (GOLDENBERG \& PRADO, 2003, p. 230).

Ao menos não há dúvida de que as manifestações políticas e intelectuais que passaram a ganhar espaço a partir de 1990, sob o dogma do mercado contra o Estado, contribuíram para aumentar a crise do Brasil. É fato que essa crise teve seu início com a elevação dos juros da dívida externa, nos anos 1980, que praticamente estrangulou os países devedores. Mas também é licito sublinhar que houve empenho de agências internacionais de risco, de organizações internacionais e de parte substancial e de governantes afins para selar a sorte do setor elétrico nacional (CANO, 2000).

Conseqüentemente, a crise da dívida externa latino-americana serviu de terreno fértil para o processo da globalização no subcontinente. E, por seu turno, a globalização serviu de justificativa para desgastes políticos, sociais e econômicos que foram considerados imanentes aos novos tempos, acima dos esforços nacionais, que seriam parcos para reverter uma espécie de lei natural que abarca todos os estados, sob os mesmos efeitos, negativos e positivos (BATISTA JÚNIOR, 1997).

A atmosfera de cultura política que fora conveniente para governos ligados à reforma institucional e a posturas cosmopolitas foram ao encontro de outro desgaste, grave para a consecução de segurança e desenvolvimento dos estados de modo geral, a relativa desconstrução do poder nacional ${ }^{13}$. É certo que o fenômeno fora latino-americano, com resultados diferentes entre os estados. No aspecto brasileiro, houve setores

13 A crise do Estado e o desgaste do poder nacional não ocorrem de modo homogêneo na América Latina. Sua gênese pode ter ocorrido nos anos 1980, a partir da moratória mexicana, mas seus desdobramentos são variados. Enquanto o Brasil teve relativo desmonte do poder nacional, mas resguardando alguns itens, países como Argentina tiveram decadência bem mais profunda em seus 
políticos que procuraram resistir à continuada reforma que, efetivamente, viessem a concluir os planos esperados pelos governos reformadores.

Mesmo assim, o que houve de empenho nas reformas institucionais, em paralelo à crise do Estado, foi suficiente para permitir a existência de contratempos suficientes para perturbar a consecução de segurança, em linhas gerais, do Estado brasileiro. Diga-se em linhas gerais porque o conceito de segurança não deve ter interpretação única, sua percepção deve ser pertinente para a questão tanto militar, modo clássico, quanto na energia, o que vale também para hidrocarbonetos. Trata-se de conceber a segurança como conceito em que devem residir preocupações não somente do meio militar, resguardando o espaço territorial, mas também a regularidade de energia, sobretudo em uma economia que ressente de desenvolvimento (HAGE, 2007).

A falta de plano coerente para sustentar o poder nacional brasileiro acabou por prejudicar aqueles setores que classicamente são valorizados na soberania nacional, as Forças Armadas. $\mathrm{Na}$ opinião de César Flores, houve premeditado plano político, a partir do governo Collor de Mello, para diminuir a importância não somente política, mas também operacional dos militares. E, para o Almirante, o resultado é a vulnerabilidade pela qual passam as regiões brasileiras, cuja presença do Estado faz-se de modo parco e dificultoso, por exemplo, a região amazônica (FLORES, 2002).

No entanto, a questão de segurança nacional não tem sido o único grande sinal de debilidade para obter-se o real poder nacional, talvez seja a mais evidente. No âmbito da política energética, há no cotidiano político brasileiro uma mescla de otimismo com falta de planejamento estratégico, que deve ser considerado ferramenta essencial tanto para a segurança em geral quanto para alimentar os elementos do poder nacional, como apego ao crescimento econômico e à tecnologia. Elementos que quando bem agregados a outros constroem o poder nacional de um país (FEROLLA \& METRI, 2006).

aspectos internos de poder. Como haviam refletido Amado Cervo e Clodoaldo Bueno, o Brasil havia feito mescla de modelos divergentes, o desenvolvimentismo com o neoliberalismo, o que dificulta a conclusão. Já a Argentina fora mais categórica na admissão das reformas liberais (CERVO \& BUENO, 2002).
Otimismo que surge em virtude da possível elevação brasileira à categoria de exportador internacional de energia por meio de sofisticada produção de etanol, biomassa e hidrocarbonetos. Estes últimos representados pelo quantum de petróleo que pode ser encontrado nas megajazidas de Tupi, na Bacia de Santos. Fator que credencia o Brasil a ator de caráter estratégico no campo da política internacional. Mas o problema é saber em que medida o Estado pode tirar proveito dessa qualificação que, se não for bem refletida, pode tornar-se um complicador ainda mais grave para a consecução de segurança e para a constituição do poder nacional.

Dessa forma, pode averiguar-se que a falta de atenção para com as questões de segurança propriamente ditas não afeta somente os termos mais urgentes da realidade brasileira, a Amazônia, o tráfico de drogas e armas, a violência urbana e outros males. O resultado para maior acuidade com as questões de segurança também pode marcar presença nos assuntos de energia, principalmente em razão da emergência de variados grupos que utilizam a violência como expressão, mas não têm, necessariamente, ligações com nacionalidades tradicionais. A pirataria da África Oriental, Somália, saqueando várias embarcações, é exemplar para ilustrar essa asserção. Embora a realidade política da África Ocidental, Angola e Nigéria, seja menos dramática que a costa leste, não há garantias que seus mares sejam imunes a violências internacionais.

Em Darc Costa pode-se encontrar perspectiva do que deveria ser a formulação de planejamento estratégico com vistas aos bens energéticos do Atlântico Sul e, ao mesmo tempo, projetar a imagem do Brasil como Estado que ao mesmo tempo prepara-se para o futuro e não se descuida de suas relações exteriores, inclusive promovendo a cooperação internacional, como segue o autor: “(a) Aproveitamento da continentalidade mediante a formatação de um processo de cooperação sulamericana $[\ldots]$. (b) $\mathrm{O}$ aproveitamento da maritimidade como instrumento de dominação do espaço marítimo do Atlântico Sul e condução do processo de mundialização ao golfo da Guiné e costa ocidental da África. (c) A criação de uma maritimidade vinculada ao oceano Pacífico que conduza a mundialização à Nova Zelândia, Austrália e costa oriental da África" (COSTA, 2001, p. 47). 
A situação política da África Ocidental e do Atlântico Sul não é indiferente para o Brasil, para quem deve formular estratégia. Preocupar-se com as imediações mencionadas é tarefa legítima para o Estado brasileiro em virtude da área que passou a ser denominada Amazônia Azul, em analogia à Amazônia florestal, com seus recursos imensos e variados que passam, a cada dia, a chamar atenção de outros agrupamentos, nacionais ou não, como contrabandistas ou cientistas e religiosos que, no fundo, estão a serviços de seus estados e privando o Brasil de seus avanços (VIDIGAL, 2006).

A Amazônia Azul é área que abarca a plataforma continental brasileira, em toda sua área de interesse, com quatro milhões de quilômetros quadrados. Em termos de aproveitamento econômico o território brasileiro estende-se para 12 milhões de quilômetros quadrados (TORRES $\&$ FERREIRA, 2009). Por enquanto, o maior ponto de atração e interesse da Amazônia Azul tem sido as imensas reservas de petróleo e gás natural. Certamente, recursos naturais que podem elevar o nível de desenvolvimento do Brasil, uma poupança que, se for bem administrada, será uma alavanca para aprimorar pesquisas de ciência, tecnologia e o poder nacional em geral.

Todavia, essa riqueza primordial pode ser mal aproveitada ou abrir novo canal de conflito que envolverá o Brasil. A razão disso é justamente a falta de preparo do item de poder nacional mais específico para a situação das novas jazidas de hidrocarbonetos, a Marinha de Guerra. Não é algo recente que a Armada brasileira demonstra preocupação com suas atuações mais elementares.

Como Domício Proença Júnior e Eugênio Diniz observaram, houve empenho mesclado com uma visão curta do processo político, para fazer que o agrupamento militar fosse "enquadrado" em um aspecto para que não houvesse mais condições intelectuais e políticas dos militares adentrarem no poder, da mesma forma como aconteceu com o movimento político-militar de 1964, pondo Castelo Branco na Presidência. É congruente citar o parecer dos autores a respeito de duas questões: "A primeira deixa transparecer um entendimento difuso do orçamento militar como espécie de pagamento que condiciona os militares a um bom comportamento e conquanto este venha a ser obtido, joga, inconscientemente, para o segundo plano as considerações acerca da suficiência dos arranjos de defesa ou da capacidade combatente resultante. Uma segunda vertente caracteriza-se por não perceber a utilidade ou a necessidade das Forças Armadas, a ponto de admitir sua eventual extinção - ainda que paulatina, a reboque da redução progressiva do orçamento" (PROENÇA JUNIOR \& DINIZ, 2001, p. 344).

Um dos meios para fazer que as Forças Armadas perdessem o ímpeto político encontrase em sua perda econômica, enxugamento do orçamento dado aos militares; atribuindo-lhes recursos suficientes apenas para os gastos mais elementares, como folha de pagamento, ensino e pensões. Já os recursos apropriados para o melhoramento do material militar ficavam ausentes. Esse tem sido um debate travado desde 1990 em que houve sinais claros do descrédito militar.

No entender do almirante Flores, é licito que haja preocupação para que a delicada democracia brasileira não seja maculada pelo autoritarismo. Talvez daí surja a comentada apreensão de alguns partidos políticos que participam da vida política nacional desde 1985 . Por outro lado, a falta de planejamento estratégico coerente com o papel que o Brasil pode representar nos negócios internacionais, por meio da energia, bota toda essa possibilidade em jogo (FLORES, 2002).

E o risco traduz-se de maneira mais clara no nível inferior que a Marinha de Guerra encontrase para fazer valer sua função, a de proteger os reais interesses nacionais, desta vez, representados pela maximização econômica dos recursos advindos da Amazônia Azul, da Bacia de Santos. Em outra instância, não deixa de ser preocupação geopolítica que apresenta nova versão para o século XXI. Não mais se pautando pelos aspectos da Guerra Fria, mas sim em consideração à necessidade que o Brasil tem. Na condição de país periférico, ou potência regional, o Brasil guarda a urgência do desenvolvimento e, por isso, não deve furtar-se da importância de melhorar seu poder nacional.

\section{CONCLUSÕES}

No decorrer deste artigo houve o intuito de fazer duas correspondências. A primeira foi a de que o processo de globalização (com sua denotação de declínio das soberanias) relacionase com a crise do Estado. Mas crise do Estado 
que ocorre de maneira desigual pelo sistema internacional, sendo os países periféricos os mais débeis na utilização do poder nacional para, justamente, amainar os efeitos provocados. E mais do que isso, poder pelo qual se coordena o desenvolvimento por meio da ciência, tecnologia, industrialização avançada, educação e outros. Na visão de Araújo Castro, é pelo preparo e pelo bom uso dos elementos do poder nacional que há elevação no nível de vida de parte da sociedade, os mais necessitados (CASTRO, 1999).

O grupo das grandes potências tem condições de suportar desgastes no campo político e econômico, caso sejam provenientes da globalização. Além disso, há possibilidades de que esse mesmo agrupamento tire proveito do fenômeno mundial, imputando valores e fazendo exigências para fazer que as unidades pobres abram mão de contestações e críticas ao sistema. No lugar de limitar a atuação dos estados industrializados, a globalização pode criar legitimidade intelectual e política para que sejam feitas reivindicações ao antigo Terceiro Mundo para que parte dos estados que o integram aceitem reformas institucionais que sejam convenientes para Hemisfério Norte, por exemplo, a abertura de mercados, as privatizações ${ }^{14}$ e a queda forte do preço das matérias-primas (GOWAN, 2003).

A segunda correspondência é que o pouco preparo e alimentação do poder nacional não somente abre espaço para efeitos nocivos da globalização, mas também contribui para o aprofundamento dos problemas de segurança.

14 Faz-se necessário explicar nestas considerações finais que por reforço do poder nacional brasileiro não implica no notadamente no estatismo ou no embate contra as privatizações. Embora seja lícito afirmar que boa parte das privatizações se deu mais com o intuito de aceitar as sugestões das organizações internacionais e investidores privados (STIGLITZ, 2003) do que para atender as reais necessidades da sociedade brasileira. Houve até efeito contrário na busca de eficiências, caso da energia elétrica (ROSA, 2001). Alimentar o poder nacional é aceitar a existência de um centro aglutinador que deve formar a grande estratégia, sob a qual se coordena os itens integrados, a economia, a educação e outros (FERREIRA, 2001). Centro que, para este último, é inexistente, pois não deve ser confundido com os ocupantes da Esplanada dos Ministérios reunidos com o presidente da República. Talvez algo que se aproxime dessa construção (nossa interpretação) seja o extinto Conselho Nacional de Segurança, fundado nos anos 1930.
Considerando uma interpretação da segurança que vá além do aspecto militar, segurança das fronteiras etc.; e sim com a importância de ligála à energia, a consecução energética, questão tão relevante para o equilíbrio político e econômico dos estados nacionais.

Se o sistema internacional é uma arena de disputas em que os estados mais bem preparados estrategicamente o dominem, então não seria incongruente imaginar, como faz Chang, que aqueles vitoriosos na corrida do desenvolvimento econômico e tecnológico, conseguindo imprimir interesses perante outros, cheguem a impedir a ascensão das pequenas potências, justamente para não perderem a cadência sobre setores fundamentais para o primeiro escalão, exemplarmente na energia e no comércio internacional. Dessa forma, os estados desenvolvidos "chutam a escada" para que os descontentes não a subam e não perturbem os de cima (CHANG, 2004).

A economia da energia tem condições de ser uma alavanca no nível de vida das sociedades, mas também pode tornar-se um fator de complicação e conflito quando não é bem administrada. A construção de regras concernentes com aquilo que o Estado espera, apoiando o espírito empresarial, atribuindo-lhe direitos necessários para a boa parceria entre o setor privado e o público deve ser uma amostra de uma boa administração. As grandes descobertas de jazidas na Bacia de Santos, com petróleo e gás natural considerados de qualidade superior, baixo teor de metais pesados, são elementos essenciais que exigem nova postura política, econômica e jurídica do Brasil; sempre na perspectiva de contribuir para a melhor ascensão internacional.

Por isso, não seria incongruente imaginar parcerias entre o poder público, munido de planejamento estratégico, com setores do empreendimento privado. Embora o convívio nem sempre seja fácil ou logre resultados esperados, é importante o mapeamento de temas e estudos em que as duas esferas possam trabalhar juntas. $\mathrm{Na}$ história recente houve avanço entre governo e sociedade, com resultados positivos, em setores de grande complexidade técnica, como a informática, dando mérito a unidades políticas periféricas em tecnologia, Brasil, Índia e Coréia do Sul (EVANS, 2004). No campo da economia da energia há possibilidades de que essa parceria seja efetiva. 
No entanto, questões de ordem geopolítica ainda são relevantes. As novas reservas na plataforma continental brasileira exigirão enormes recursos financeiros e políticos para dar serventia aos insumos dali explorados. Financeiros porque será volumoso investimento que superará a estimativa tanto do Palácio do Planalto quanto da Petrobrás. Também haverá custos políticos em virtude dos cuidados de ordem geopolítica que deverá ser integrada a um relevante projeto estratégico, averiguando a situação de segurança na área do Atlântico Sul e as relações que o Brasil tem com a África Ocidental.

Por fim, a segurança energética com que o Brasil terá de preocupar-se não é desligada da esfera internacional. Três itens são mencionados aqui. Primeiro, porque parte dos investimentos para o setor de energia terá origem no exterior. Segundo, é em virtude das relações de parceria que a estatal nacional tem com empresas internacionais. E terceiro, por causa da cadência que o complexo Nova Iorque-Londres exerce na economia, negociação e logística do petróleo, concentrando poder (SÉBILLE-LOPEZ, 2006).

Isso porque não é totalmente correto afirmar que os estados produtores de petróleo, boa parte deles membros da Organização dos Países Produtores de Petróleo (OPEP), Arábia Saudita, Venezuela, Kuwait e outros, gozam de proeminência na economia internacional. Após a crise do petróleo, de 1973, as potências dependentes da exportação do óleo procuraram modificar a situação que lhes deixaram vulneráveis. $\mathrm{O}$ efeito daquela crise para os Estados Unidos, Grã-Bretanha e Japão foi desmontar as infraestruturas que, até então, funcionavam nas áreas produtoras para serem transferidas para os consumidores. Assim se deu com as transferências de refinarias, comercialização e transporte dos membros da OPEP para a América do Norte e Europa Ocidental.
Com efeito, a OPEP pode concentrar e politizar o óleo cru, mas terá grande dificuldade em fazer boicote, pois seus sócios não detêm tecnologia nem logística suficientes para agregar valor ao produto, cabendo às instituições de Nova Iorque e de Londres efetuarem o que os árabes, por exemplo, não podem. Esse é um tema que não deve ser ignorado pelo Brasil, mesmo que o insumo seja o etanol. Em síntese, o que vale para as negociações dos hidrocarbonetos estende-se também para os combustíveis renováveis.

Tudo isso leva a observar que o jogo em que o Brasil tenciona entrar, negociando energia na economia internacional, não será fácil, sobretudo para um Estado considerado periférico e com limitados elementos de poder. Eis a razão para atribuir-se maior importância na reformulação do poder nacional, salutar para a nova fase de relações internacionais que podem ser benéficas para o País.

A globalização não precisa ser interpretada apenas como instrumento de ideologização a favor de determinados grupos. Ricupero e Ianni refletiram sobre o assunto. Ela pode ser o meio pelo qual se elevará um novo conceito de cidadania, fomentando uma sociedade civil internacional (COSTA, 2001). Mas a globalização não pode ser mistificada na condição de fenômeno natural e acima das capacidades políticas das sociedades, usando ou sendo usada, para justificativas que perturbam propostas e projetos nacionais, imputando-lhes juízos negativos. Em parte, foi isso que aconteceu com alguns estados em desenvolvimento que se conformaram a um destino menor e a favor de grupos que tiraram proveito de um ciclo econômico que mostrou sinais de esgotamento, caso da Indonésia dos anos 1990 e da Argentina em 2001. No campo dos assuntos energéticos, a globalização é questão que necessita ser reavaliada.

José Alexandre Altahyde Hage (alexandrehage@hotmail.com) é Doutor em Ciência Política pela Universidade Estadual de Campinas (Unicamp) e Professor de Política Internacional na Universidade Federal de São Paulo (Unifesp).

\section{REFERÊNCIAS BIBLIOGRÁFICAS}

ARENDT, H. 1989. As origens do totalitarismo: anti-semitismo, imperialismo, totalitarismo. São Paulo: Companhia das Letras.
ARON, R. 1986. Guerra e paz entre as nações. $2^{\mathrm{a}}$ ed. Brasília: UNB. 
BALBONTíN. P. R. 1999. La crisis eléctrica en Chile. Antecedentes para una evaluación de la Insecontitucionalid Regulatoria. Cepal-Serie Recursos Naturales y Infra-Estructura, Santiago, n. 5, p. 1-84. Disponível em: http:// www.eclac.cl/publicaciones/xml/0/4370/ lc11284e.pdf. Acesso em: 16.dez.2011.

BATISTA JÚNIOR, P. N. 1997 Os mitos da globalização. São Paulo: USP.

BENJAMIN, C. 2001. Foi loucura, mas houve método nela: gênese, dinâmica e sentido da crise energética brasileira. In: LESSA, C. (org.). O Brasil à luz do apagão. Rio de Janeiro: Palavra e Imagem.

BERMANN, C. 1991. Os limites dos aproveitamentos energéticos para fins elétricos: uma análise política da questão energética e suas repercussões sócioambientais no Brasil. Campinas. Tese (Doutorado em Engenharia Mecânica). Universidade Estadual de Campinas.

CAMPOS, R. 1994. A lanterna na popa: memórias. Rio de Janeiro: Topbooks.

CANO, W. 2000. Soberania e Economia Política na América Latina. Campinas: UNICAMP.

CAstro, J. A. 1999. O poder nacional. Limitações de ordem interna e externa. Parcerias Estratégicas, Brasília, n. 6, p. 216240, mar. Disponível em: http:// s e er.cge e.org.br/index.ph p/ parcerias_estrategicas/article/viewFile/65/57. Acesso em: 16.dez.2011.

CAUBET, C. 1991. As grandes manobras de Itaipu. São Paulo: Acadêmica.

CERVO, A. L. \& BUENO, C. 2002. História da política exterior do Brasil. Brasília: UNB.

CHANG, H. 2004. Chutando a escada. São Paulo: UNESP.

COSTA, D. 2001. A estratégia nacional de energia. In: LESSA, C. (org.). O Brasil à luz do apagão. Rio de Janeiro: Palavra e Imagem.

2004. Estratégia nacional: a cooperação sul-americana. São Paulo: Paz e Terra.

COUTO E SILVA, G. 1981. Planejamento estratégico. Brasília: UNB.
DOMINGUES, J. M. 2007. Aproximações à América Latina: desafios contemporâneos. Rio de Janeiro: Civilização Brasileira.

EVANS, P. 2004. Autonomia e parceria: estados e transformação industrial. Rio de Janeiro: UFRJ.

FEROLLA, S. \& METRI, P. 2006. Nem todo o petróleo é nosso. São Paulo: Paz e Terra.

FERRAZ, O. F. 1981. Paulo Afonso impediu a explosão social no Nordeste. In: MOTTA, L. D. (org.). História vivida: documentos abertos. São Paulo: O Estado de S. Paulo.

FERREIRA, O. 2001. Crise da política externa: renovação ou subordinação? Rio de Janeiro: Revan.

FLORES, M. C. 2002. Reflexões estratégicas. São Paulo: Realizações.

FREUND, J. 1986. L'essence du politique. $2^{\mathrm{a}} \mathrm{ed}$. Paris: Sirey.

GOLDENBERG, J. \& PRADO, L. T. 2003. Reforma e crise do setor elétrico no período FHC. Tempo Social, São Paulo, v, 15, n. 2, p. 219-235, nov. Disponível em: http:// www.scielo.br/pdf/ts/v15n2/a09v15n2.pdf. Acesso em: 16.dez.2011.

GOWAN, P. 2003. A roleta global: a aposta faustiniana de Washington para dominar o mundo. Rio de Janeiro: Record.

GRAY, J. 1999. O falso amanhecer: os equívocos do capitalismo global. Rio de Janeiro: Record.

GRÜN, R. 2005. Apagão cognitivo: a crise energética e sua Sociologia. Dados, Rio de Janeiro, v. 48, n. 4, p. 891-928. Disponível em: http://www.scielo.br/pdf/dados/v48n4/ 28481.pdf. Acesso em: 16.dez.2011.

HAGE, J. A. 2007. Bolívia, Brasil e a guerra do gás. Curitiba: Juruá.

HARVEY, D. 2004. O novo imperialismo. São Paulo: Loyola.

HASLAM, J. 2006. A necessidade é a maior virtude: o pensamento realista nas Relações Internacionais. São Paulo: M. Fontes.

HAYEK, F. 1986. Os caminhos da servidão. São Paulo: Instituto Liberal. 
HOBSBAWN, E. 1994. A era dos extremos: o breve século XX. São Paulo: Companhia das Letras.

IANNI, O. 1997. Teorias da globalização. Rio de Janeiro: Civilização Brasileira.

KEYNES, J. M. 2002. As conseqüências econômicas da paz. Brasília: UNB.

LEITE, A. D. 1997. A energia do Brasil. Rio de Janeiro: Nova Fronteira.

MARX, K. \& ENGELS, F. 1982. O Manifesto do Partido Comunista. In: MARX, K. \& ENGELS, F. Obras completas. V. 1. Lisboa: Avante.

POLANYI, K. 2000. A grande transformação: as origens da nossa época. $2^{\mathrm{a}}$ ed. Rio de Janeiro: Campus.

PROENÇA JÚNIOR, D. \& DINIZ, E. 2001. Segurança e estudos estratégicos. In: BRIGAGÃO, C. (org.). Estratégia das Relações Internacionais. Rio de Janeiro: Altiplano.

RICUPERO, R. 2002. A globalização em questão. São Paulo: Senac.

RIFKIN, J. 2002. A economia do hidrogênio. São Paulo: M, Books.

ROSA, L. P. 2001. Apagão: como veio, como sair dele? Rio de Janeiro: Revan.

SANTOS, E. M. 2002. Gás natural. São Paulo: Annablume.
SCHMMITT, C. 1992. O conceito do político. Petrópolis: Vozes.

SCHUTTE, G. R. 2004. O elo perdido: Estado, globalização e indústria petroquímica no Brasil. São Paulo: Annablume.

SÉBILLE-LOPEZ, F. 2006. Geopolíticas do petróleo. Lisboa: Piaget.

SOLNIK, A. 2001. A guerra do apagão. São Paulo: Senac.

STIGLITZ, J. E. 2003. Os exuberantes anos 90: uma nova interpretação da década mais próspera da história. São Paulo: Companhia das Letras.

TAVARES, M. C. 1999. Império, território e dinheiro. In: FIORI, J. L. (org.). Estados e moedas no desenvolvimento das nações. $3^{\mathrm{a}} \mathrm{ed}$. Petrópolis: Vozes.

THOMPSON, G. \& HIRST, P. 2002. Globalização em questão. Petrópolis: Vozes.

TORRES, L. C. \& FERREIRA, H. S. Amazônia azul: a fronteira brasileira no mar. Brasília: Marinha do Brasil. Disponível em: www.mar.mil.br/dhn/dhn/amazoniazul.pdf. Acesso em: 16.dez.2011.

VIDIGAL, A. A. F. (org.). 2006. Amazônia Azul: o mar que nos pertence. Rio de Janeiro: Record.

VIEIRA, J. P. 2007. O antivalor: um estudo da energia elétrica. São Paulo: Paz e Terra.

WALTZ, K. 2002. Teoria de Relações Internacionais. Lisboa: Gradiva. 
BRAZILIAN ENERGY POLICY IN AN ERA OF GLOBALIZATION: ENERGY AND CONFLICTS OF A DEVELOPING STATE

\section{José Alexandre Altahyde Hage}

The purpose of this article is to analyze how developing States such as Brazil are faring in the ambit of globalization.. We intend to show that globalization has largely not contributed in advantageous ways to developing states, due to their difficulties in building national power.. In these cases, globalization itself can be used as a means to concentrate influence within industrialized States, making relationships difficult on both sides. We also intend to examine how these issues correspond to the role Brazil may represent as large scale ethanol and oil producer. Finally, we. seek to understand how the country can become a major producer of energy while at the same time building national power in the age of globalization. .

KEYWORDS: Brazilian National Power; Globalization; International Politics; Energy. 